\title{
STARZ-DRP: A STRUCTURED FRAMEWORK FOR TEACHING COMMUNITY PHARMACISTS TO COUNSEL SELF-CARE CUSTOMERS
}

\author{
NAZRI NORDIN ${ }^{*}$, MOHAMED AZMI HASSALI ${ }^{2}$, AZMI SARRIFF ${ }^{3}$ \\ ${ }^{1}$ Post Graduate Student (PhD), ${ }^{2}$ Professor of Social and Administrative Pharmacy Discipline; ${ }^{3}$ Professor of Clinical Pharmacy Discipline, \\ ${ }^{4}$ School of Pharmaceutical Sciences, Universiti Sains Malaysia, 11000 Minden, Pulau Pinang, Malaysia \\ *Email: nazri@i-raey.com
}

Received: 30 Aug 2017 Revised and Accepted: 02 Nov 2017

ABSTRACT

Objective: Aim of this study is to take a look at the community pharmacists' (CPs) self-rating confidence of advocating self-care customers using before and after attending a STARZ-DRP training workshop.

Methods: CPs ( $\mathrm{n}=231)$ in the state of Penang had been invited via e-mail to engage in a STARZ-DRP training workshop. CPs had been trained to assess individual features and analyse the facts and figures before formulating a triage action plan. A self-administered questionnaire to evaluate CPs' self-confidence to performing self-care counselling had been handed out before and after the workshop.

Results: Twenty CPs $(8.7 \%)$ had responded to the invitation via e-mail. It was noted that CPs' self-rating confidence to performing self-care counselling making use of STARZ-DRP as a framework were improved in all domains reflected in the questionnaire. Among significant improvements $(\mathrm{p}<0.05)$ noted were making triage decision, consistently assessing individual features, and identifying actual or potential origins of the medical problem.

Conclusion: CPs' self-confidence to performing self-care counselling making use of STARZ-DRP as a framework to advocate self-care customers is enhanced after turning up at the training workshop. It reflects the future use of STARZ-DRP as a potential framework to help out CPs to formulate a triage action plan for self-care customers.

Keywords: STARZ-DRP, Self-care counselling, Community pharmacist, Triage decision, Self-confidence

(C) 2017 The Authors. Published by Innovare Academic Sciences Pvt Ltd. This is an open-access article under the CC BY license (http://creativecommons.org/licenses/by/4.0/) DOI: http://dx.doi.org/10.22159/ijpps.2017v9i12.22330

\section{INTRODUCTION}

Trying to teach a counselling framework to the community pharmacists (CPs) without first builds self-confidence is like constructing a house with fragile pillars. It might have a nice coat of colourful paints, but it can shake if the wind roars harder. Therefore, self-confidence is a fundamental basis from which CPs' counselling skills can continue to grow.

It is noted that there are several counselling frameworks which are accessible to make it easier for CPs to advocate self-care customers. Such frameworks are WWHAM, ASMETHOD, SIT DOWN SIR, ENCORE, CHAPS-FRAPS and QuEST/SCHOLAR [1-6]. Each framework has some limitation as pointed out in another review article [7]. For example, WWHAM, ASMETHOD and SIT DOWN SIR methods yield limited information for CPs to make an accurate triage action plan. In contrast, QuEST/SCHOLAR method yields exceed information for CPs to make triage action plan but require more information about individual features in order to assist CPs to perform the role to pinpoint actual or potential origins of drug-related problems. While the leadership pharmacy communities might pay particular attention to passion, communication, and empowerment, they turn a blind eye to assess individual features and document their triage action plan. Therefore, STARZ-DRP has been initiated as an advanced counselling framework which has potential to eradicate limitation noted in other aforementioned counselling frameworks [7]. Interestingly, STARZDRP has been displayed in a simple printed form which is known as 'Pharmacy Self-care Advice Form' as illustrated in fig. 1 in order to make it easier for CPs to assess individual features and document their evaluation and triage action plan for future review. In contrast, other frameworks are drafted as a simple mnemonic to remember in absence of a printed form. As a result, there is potential for failure since CPs might not keep an image in mind of either individual features or triage action plan after some time. Therefore, STARZ-DRP has been nominated as a framework to make it easier for CPs in Malaysia to perform self-care counselling in community pharmacy settings. Furthermore, STARZ-DRP is noted to have potential to eradicate all limitation discovered in other aforementioned frameworks.

The aim of this study is to take a look at CPs' self-rating confidence to performing self-care counselling making use of STARZ-DRP as a framework before and after attending our training workshop. The rationale of this study is the fact that it can determine the future use of STARZ-DRP as a counselling framework to make it easier for CPs to perform extended services in community pharmacy settings.

\section{MATERIALS AND METHODS}

STARZ-DRP is a simple mnemonic for CPs to remember a step-bystep approach which is necessary to acquire as much as individual specific data in order to make it easier for CPs to determine the origin of the medical disorder and initiate a triage action plan [7] This methodical modus operandi is derived from the pharmaceutical care concept [8]. Each word as portrayed in table 1 is representing questions about the individual features, medical and medication histories. It is critical to evaluate the data because it can help out CPs to determine the origin of the medical disorder is not caused by medication use. Consequently, CPs have to determine if the medical disorder requires medications or immediate medical attention. Such events are illustrated as a triage action plan [9]. Making a triage action plan is a distinctive service that CPs should execute in community pharmacy settings as it has potential to bring advantage to individuals who determine to self-medicate [10].

Malaysian Pharmaceutical Society had worked jointly with the researchers to conduct a workshop to train CPs to use STARZ-DRP as a framework to perform self-care counselling. The workshop was conducted on $23^{\text {rd }}$ July 2017 from 9.00 am to $4.30 \mathrm{pm}$ at Safira Country Club, Seberang Jaya, Penang. In the workshop, CPs had been taught in detail about STARZ-DRP and its potential to make it easier for CPs to perform self-care counselling in community pharmacy settings. The workshop ended with a group discussion focusing on actual case studies which were illustrated by an invited practitioner. 
An invitation letter was e-mailed two months earlier to all CPs $(n=231)$ in the state of Penang. Those who responded to the invitation e-mail would have to attend earlier to register their attendance before $9.00 \mathrm{am}$. Upon registration, the participants were instructed to fill up a self-rating confidence questionnaire and return back to the researchers before the workshop started.

This questionnaire was derived from a validated questionnaire which used to determine self-rating of confidence among undergraduate students who were trained to use other counselling framework was known as QuEST/SCHOLAR to perform self-care counselling [6]. A permission to use the questionnaire in our study had been obtained from the responsible author. At the end of the workshop, the participants would have to fill up the identical questionnaire and return it back to the researcher.

All data had been computed in International Business Machine of Statistical Package for the Social Sciences (IBM SPSS) version 22.
Descriptive statistical analysis was used to learn about the demographic data of CPs and Pair Sample T-test was used to compare mean scores between pre-and post-training of CPs' selfconfidence on future delivering self-care counselling. Significant statistical was set at $\mathrm{p}<0.05$.

\section{RESULTS}

Twenty CPs (8.7\%) had responded to the invitation via e-mail. Their demographic data was reflected in table 2 . Table 3 disclosed mean scores (pre-and post- training) for CPs' self-rating confidence to perform selfcare counselling making use of STARZ-DRP as a framework. CPs' perceptions to perform self-care counselling were improved for all domains (table 3). It was noted that CPs' self-rating confidence was low for domain \# 8, 11, and 12. Interestingly, it was noted a significant improvement of CPs' self-confidence to perform self-care counselling after attending the training as reflected by the mean scores (posttraining) for domains \# 2,3, 8, 10,11,12, 14, and 15.

Table 1: Definition of letters in STARZ ${ }^{*}$

\begin{tabular}{ll}
\hline Letter & Description \\
\hline $\mathrm{S}$ & Symptom presentation refers to subjective evidence of health problem perceived by the patient. \\
$\mathrm{T}$ & Time of onset and duration of the present symptoms. \\
$\mathrm{A}$ & Associated symptoms refer to patient symptoms explored and determined by the pharmacist during the interview. It does not \\
& refer to the symptoms presented earlier by the patient. This is done by using the pictorial documentation form as depicted in fig. 1. \\
& To aid and ease the pharmacist during the interview, the human body is arbitrarily divided into four regions: (i) Front: the part of \\
the body facing the pharmacist (asking for symptoms like bloating, heartburn, nausea, vomiting, breathlessness, etc), (ii) Back: \\
(asking for symptoms like lower and upper back pain, shoulder pain, and neck pain), (iii) Upper (head) (asking for symptoms like \\
headache, dizziness, problems with sleep, etc), (iv) Lower (asking for symptoms like numbness in both legs and hands, \\
constipation, and swollen feet). Perhaps, the method is likened to a filtering or screening process to rule out the presence of severe \\
symptoms. \\
Recurrence problem refers to the symptoms have been treated before, specifically when the symptoms recur and persist despite the \\
treatment prescribed. \\
Zoom into the patient's medication experience refers to information collected by the pharmacist related to any medical problems (e. g., \\
hypertension, diabetes, hyperthyroid, etc), medication utilization (e. g., use of prescription and non-prescription drugs, and herbal \\
supplements), immunization history, allergies, drug sensitivities, drug side effects, adverse reactions, and the consumption of alcohol, \\
caffeine and tobacco.
\end{tabular}

\#This is not a diagnostic tool, rather it is a format with the purpose of organizing a community pharmacist's knowledge in a manner that allows him/her to begin identifying the actual and potential drug-related problems and subsequently referring triage patients to the appropriate health care professionals,

*The patient's vital signs will be measured when necessary. At times, the patient's blood pressure, pulse rate, and body temperature are measured to aid the pharmacist in assessing the appropriateness of symptoms for self-medication.

Table 2: Demographic data of participants

\begin{tabular}{ll}
\hline Demographic information & Participants, **n \\
\hline Age, ${ }^{*}$ mean \pm SD & $32.65 \pm 9.60$ \\
Gender & \\
Female & $45.0 \%$ \\
Male & $55.0 \%$ \\
Race & $75.0 \%$ \\
Chinese & $20.0 \%$ \\
Malay & $5.0 \%$ \\
Punjabi & \\
Marital status & $60.0 \%$ \\
Single & $40.0 \%$ \\
Married & \\
Years' graduating from a pharmacy school & $60.0 \%$ \\
Less than 5 y & $40.0 \%$ \\
5 y or more & \\
Years' experience as a community pharmacist & $60.0 \%$ \\
Less than 5 y & $40.0 \%$ \\
5 y or more & \\
\hline
\end{tabular}

${ }^{*}$ mean in years; ${ }^{* *} \mathrm{n}=20 ; \mathrm{SD}=$ standard deviation

\section{DISCUSSION}

Interestingly, it is noted that CPs' perception of self-confidence to perform self-care counselling is significantly enhanced as disclosed in domain \# 2, 3, 8, 10, 11, 12, 14, and 15 (table 3) after attending the training. In addition, most of its mean scores (post-training) are noted higher than mean scores (post-training) disclosed in other study performed in the United States of America [6]. A potential 
factor might determine such the mean scores is their experience of practice. It is noted that the earlier study is involving undergraduate students who are trained to use QuEST/SCHOLAR as a counselling framework.

(3). Sign and Symptom Assessment

\begin{tabular}{|c|c|c|}
\hline $\begin{array}{c}\text { The presenting signs/symptoms is/are } \\
\text { NOT easily } \\
\text { recognized as self-treatable condition? }\end{array}$ & $\begin{array}{c}\text { The presenting signs/symptoms is/are } \\
\text { too serious } \\
\text { for self-treatment? } \\
\square \text { Yes } \square \text { No }\end{array}$ & $\begin{array}{c}\text { The patient requires further medical } \\
\text { examination? }\end{array}$ \\
& $\square$ Yes $\square$ No & $\square$ Yes $\square$ No \\
\hline
\end{tabular}

\begin{tabular}{|c|c|c|}
\hline \multicolumn{3}{|c|}{ (4). Pharmacy Care Plan } \\
\hline 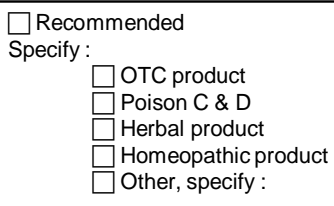 & $\begin{array}{l}\square \text { Referral } \\
\text { Specify : } \\
\qquad \begin{aligned} & \text { General practitioner (GP) } \\
& \square \text { Hospital } \\
& \square \text { Conditional referral to GP } \\
& \text { (if not better in \# of days) }\end{aligned}\end{array}$ & $\begin{array}{l}\square \text { Health screening/promotion } \\
\text { Specify: } \\
\square \text { BP measurement } \\
\square \text { Pregnancy test } \\
\square \text { Blood cholesterol } \\
\square \text { Blood/Urine glucose } \\
\square \text { Other, specify : }\end{array}$ \\
\hline List of product : & Reason for referral : & Describe advice : \\
\hline
\end{tabular}

(5). Follow-up

Provide reasons and how to :

B. States Drug-Related Problem

\begin{tabular}{|c|c|c|c|}
\hline Indication & Effectiveness & Safety & Compliance \\
\hline $\begin{array}{l}\square \text { No indication for non- } \\
\text { prescription medication } \\
\square \text { Uncertainty about the } \\
\text { indication of drug } \\
\square \text { Need for additional } \\
\text { therapy }\end{array}$ & $\begin{array}{l}\square \text { Inappropriate drug choice } \\
\square \text { Dose too low } \\
\square \text { Ineffective therapy } \\
\square \text { Interference with medical } \\
\text { therapy by alcohol } \\
\text { /caffeine/smoking consumption } \\
\square \text { Lack of understanding of } \\
\text { the medication } \\
\square \text { Monitoring required }\end{array}$ & $\begin{array}{l}\square \text { Use of medication to } \\
\text { which the patient is allergic } \\
\square \text { Adverse drug events } \\
\square \text { Potential drug-disease } \\
\text { interaction } \\
\square \text { Potential drug-drug } \\
\text { interaction } \\
\square \text { Dose too high }\end{array}$ & $\begin{array}{l}\square \text { Problems arising from } \\
\text { financial impact of therapy } \\
\square \text { Interference with medical } \\
\text { therapy by cultural/religious } \\
\text { beliefs } \\
\square \text { Failure of the patient to } \\
\text { adhere to labeling instructions } \\
\square \text { Others }\end{array}$ \\
\hline
\end{tabular}

Fig. 1: Pharmacy self-care advice form

Table 3: Pre-and post-training mean scores noted in Self-rating Questionnaires

\begin{tabular}{|c|c|c|c|}
\hline & Pre-training & Post-training & P value \\
\hline 1. I can accurately identify a patient's problem. & $3.75(0.64)$ & $3.95(0.76)$ & 0.297 \\
\hline $\begin{array}{l}\text { 2. I can consistently ask about a patient's medical conditions, allergies, and } \\
\text { concurrent medications. }\end{array}$ & $4.00(0.56)$ & $4.35(0.59)$ & 0.031 \\
\hline $\begin{array}{l}\text { 3. I can correctly determine whether a patient can self-treat with an OTC product } \\
\text { or should be referred to their physician. }\end{array}$ & $3.65(0.93)$ & $4.30(0.57)$ & 0.024 \\
\hline 4. I can recommend product(s) that will address all of a patient's symptom(s). & $3.75(0.79)$ & $4.00(0.72)$ & 0.234 \\
\hline 5. I can accurately counsel a patient on an OTC product. & $4.10(0.55)$ & $4.15(0.67)$ & 0.748 \\
\hline 6. 6. I can accurately counsel a patient on what a speci fic OTC medication is for. & $4.00(0.65)$ & $4.30(0.57)$ & 0.055 \\
\hline 7. I can accurately counsel a patient on how to take a speci fic OTC medication. & $4.05(0.51)$ & $4.20(0.52)$ & 0.186 \\
\hline
\end{tabular}




\begin{tabular}{|c|c|c|c|}
\hline $\begin{array}{l}\text { 8. I can accurately counsel a patient on when they should start seeing a bene fit } \\
\text { from a specific OTC medication. }\end{array}$ & $3.50(0.76)$ & $4.05(0.60)$ & 0.008 \\
\hline $\begin{array}{l}\text { 9. I can accurately counsel a patient on adverse effects that may occur with a } \\
\text { specific OTC medication. }\end{array}$ & $3.60(0.75)$ & $4.05(0.76)$ & 0.058 \\
\hline $\begin{array}{l}\text { 10. I can accurately counsel a patient on when to follow up with their physician } \\
\text { after recommending an OTC medication. }\end{array}$ & $3.60(0.75)$ & $4.15(0.81)$ & 0.012 \\
\hline $\begin{array}{l}\text { 11. I can identify drug allergies that affect product selection for a self-care } \\
\text { patient. }\end{array}$ & $3.30(0.73)$ & $4.05(0.60)$ & 0.004 \\
\hline $\begin{array}{l}\text { 12. I can identify medications a patient may be taking that affect product } \\
\text { selection for a self-care patient. }\end{array}$ & $3.50(0.69)$ & $4.10(0.72)$ & 0.007 \\
\hline $\begin{array}{l}\text { 13. I can identify concomitant disease states that affect product selection for a } \\
\text { self-care patient. }\end{array}$ & $3.60(0.68)$ & $3.85(0.74)$ & 0.234 \\
\hline $\begin{array}{l}\text { 14. I can describe patient speci fic factors that influence the selection of an OTC } \\
\text { product and the dosage form. }\end{array}$ & $3.50(0.51)$ & $4.25(0.55)$ & $<0.001$ \\
\hline $\begin{array}{l}\text { 15. I can recommend the appropriate product for any patient with cold } \\
\text { symptoms. }\end{array}$ & $3.85(0.49)$ & $4.30(0.57)$ & 0.016 \\
\hline 16. I can recommend the appropriate product for any patient with constipation. & $4.10(0.64)$ & $4.30(0.57)$ & 0.258 \\
\hline 17. I can recommend the appropriate product for any patient with pain. & $3.90(0.64)$ & $4.20(0.52)$ & 0.055 \\
\hline 18. I can recommend the appropriate product for any patient with diarrhea. & $4.10(0.55)$ & $4.30(0.57)$ & 0.163 \\
\hline 19. I can recommend the appropriate product for any patient with ysmenorrhea. & $3.65(0.81)$ & $3.90(0.72)$ & 0.135 \\
\hline 20. I can recommend the appropriate product for any patient with fever. & $4.10(0.55)$ & $4.25(0.64)$ & 0.419 \\
\hline 21. I can recommend the appropriate product for any patient with in flammation. & $3.95(0.61)$ & $4.20(0.62)$ & 0.135 \\
\hline
\end{tabular}

1 = strongly disagree; 2 = disagree; 3 = neutral; 4 = agree; 5 = strongly agree, OTC = over-the-counter drug

It is believed that they might not have the knowledge or skill acquired by experience over a period of time. Nevertheless, the training which is involving the undergraduate students is able to enhance their perception of self-confidence to perform self-care counselling. Their mean scores show a significant improvement in attentiveness for all domains.

Nevertheless, it is noted that CPs in our study require more training in order to enhance their self-confidence to perform self-care counselling. As noted in the earlier study, the undergraduate students are involving in series of quizzes which enable them to enhance their knowledge and skills to consistently assessing individual specific data and improve their self-confidence to perform their future duties [6]. Therefore, their mean scores are significantly noted improving in all domains. In contrast, CPs in our study are involving in a group discussion without attending any quizzes. As a result, CPs are potentially demonstrating lower perception of selfconfidence to perform self-care counselling as reflected in domain \# 2 (table 3) when comparing with the earlier study. Therefore, a subsequent study should be coordinated to disclose any significant improvement in all domains after 3 mo attending the training.

It is also noted that CPs in our study execute higher mean scores (post-training) in domain \# 8 and 10 (table 3) than noted in the earlier study [6]. A potential factor which can determine such mean scores is the fact that STARZ-DRP is a counselling framework which requires CPs to get rid of actual or potential factors which can initiate customers to violate medication therapy plan such as failure to read the printed label or comply with medication therapy regimen [7]. Such factors are necessary to be documented in a piece of a printed paper (see fig. 1) in order to put CPs in mind of aforementioned factors which causes the medication therapy to failure. It is noted that such proceeding can make it easier for CPs to initiate an up to date medication therapy regimen such as its mechanism, side effects, and cost. Consequently, CPs exhibit a significant improvement of their self-rating confidence to perform self-care counselling as reflected in aforementioned domains.

Events such as allergies episode, individual features, and medication use are indisputable factors which might have potential to be the origins of medical disorders [11-13]. It is mandatory for CPs in our study to explore such events in order to eradicate the origins. Consequently, CPs exhibit a significant improvement in domain \# $11,12,14$, and 15 (table 3). Interestingly, the mean scores (postcourse) are noted higher than the earlier study [6]. A potential factor which determines such mean scores is the fact that CPs are acquiring a practical experience over a period of time. Such event might cause CPs to learn something by example or experience. For example, the sleeping problem is noted as the potential origin of lower resistance to viral infection [14]. However, CPs might be too late to catch such aspect unless it is mandatory for CPs to explore the aforementioned aspect. Such event is indispensable in our training. Consequently, CPs might give the customer information on this particular aspect to eradicate it or refer him to GPs for an antiviral medication.

Our study determines the value of a training workshop to make it easier for CPs to execute self-care counselling in community pharmacy settings. It is noted that CPs' self-rating confidence to perform such role is improved in many aspects as disclosed in table 3. Such a result is also noted in an earlier study performed in Canada [15]. The interactive workshop enables the pharmacists to intensify their self-efficacies to assess individual particular features and their impression to keep either verbal or non-verbal data in a piece of printed paper or electronic device. Such events disclose the potential among the pharmacists to render a wide range of extended services in either hospital or non hospital setting.

In addition, our training workshop enables CPs to take more responsibilities with each triage action plan. Such an event can initiate a working relationship with GPs when CPs begin to refer customers who require either immediate medical attention or prescription medications. Interestingly, the phenomenon is also noted in the United Arab Emirates, Australia, Hong Kong, and Sudan [16-19]. It is noted that CPs in the countries have pointed out such working relationship can bring rewards to customers who require advanced advice. Such responsibilities in different extended pharmacy services are also noted in other countries like the United Kingdom, South Africa, Hong Kong, Australia, United Arab Emirates, China, and India [20-28]. Obviously, CPs in the countries would like to execute more services rather than sell medications over the counter.

\section{CONCLUSION}

It is noted that the training workshop is able to boost CPs' selfconfidence to perform self-care counselling making of use STARZDRP as a framework. It is signalling that STARZ-DRP can make it easier for CPs to perform extended services in community pharmacy settings. Interestingly, STARZ-DRP is intensifying values of another counselling framework is known as QuEST/SCHOLAR.

\section{LIMITATION}

It is preferable if the study can enrol more CPs to engage in the training workshop. Their participation might have the capacity to possess an effect on the mean scores. Consequently, it is potential to see something from a particular perspective.

\section{ACKNOWLEDGMENT}

We are grateful to those who help us to finish up this article. 


\section{AUTHORS CONTRIBUTION}

A\#1 conducted, collected and analysed data collection. A\#2 monitored the quality of data collection. A\#3 provided expertise in extra comments.

\section{CONFLICT OF INTERESTS}

Authors declare no conflict of interest in the study

\section{REFERENCES}

1. Blenkinsopp A, Paxton P, Blenkinsopp J. Symptoms in the pharmacy: a guide to the management of common Illness. 5th. Eds. Blackwell Publishing, Oxford, UK; 2005. p. 1-13.

2. Edwards C, Stillman P. Minor illness or major disease? The clinical pharmacist in the community. $4^{\text {th }}$ Eds. Pharmaceutical Press; London: 2006. p. 1-10.

3. Rutter P. Community pharmacy. Symptoms, Diagnosis and Treatment. Churchill Livingstone, An Imprint of Elsevier Limited; 2004. p. IX-XI.

4. Rutter PM, Horsley E, Brown DT. Evaluation of community pharmacists' recommendations to standardized patient scenarios. Ann Pharmacother 2004;38:1080-5.

5. McCallian DJ, Cheigh NH. The pharmacist's role in self-care. J Am Pharm Assoc 2002;42:S40-1.

6. Shauna MB, Kirby J, Conrad WF. A structured approach for teaching students to counsel self-care. Patients Am J Pharm Educ 2007;71:1-7.

7. Sarriff A, Nordin N, Hassali MA. STARZ-DRP: a step-by-step approach for pharmacy triage services. Mal J Pharm 2011;1:311-25.

8. Cipolle RJ, Strand LM, Morley PC. Pharmaceutical care practice: the clinician's guide. $2^{\text {nd }}$ ed. New York: McGraw-Hill; 2004.

9. Keegan J. The Face of Battle. New York: Viking Press; 1976. p. 267-9.

10. Curley LE, Moody J, Gobarani R, Aspden T, Jensen M, McDonald M, et al. Is there potential for the future provision of triage services in community pharmacy? J Pharm Policy Prac 2016;9:29.

11. Zukiewicz-Sobczak WA, Wroblewska P, Adamczuk P, Zwolinski J, Oniszczuk A, Wojtyla-Buciora P, et al. Drugs as important factors causing allergies. Postep Derm Alergol 2015;XXXII:388-92.

12. Wang PS, Bohn RL, Knight E, Glynn RJ, Mogun H, Avorn J. Noncompliance with antihypertensive medications. the impact of depressive symptoms and psychosocial factors. J Gen Intern Med 2002;17:504-11.

13. Wallace JL. How do NSAIDs cause ulcer disease? Baillieres Best Pract Res Clin Gastroenterol 2000;14:147-59.

14. Cohen S, Doyle WJ, Alper CM, Janicki-Deverts D, Turner RB. Sleep habits and susceptibility to the common cold. Arch Intern Med 2009;169:62-7.
15. Guirguis LM, Lee S, Sanghera R. Impact of an interactive workshop on community pharmacists' beliefs toward patient care. Int J Clin Pharm 2012;34:460-7.

16. Rayes IK, Abduelkarem AR. A qualitative study exploring physicians' perceptions on the role of community pharmacists in Dubai. Pharm Pract 2016;14:738.

17. Hoti K, Hughes J, Sunderland B. An expanded prescribing role for pharmacists-an Australian perspective. Aust Med J 2011;4:236-42.

18. Wong FYY, Chan FWK, You JHS, Wong ELY, Yeoh EK. Patient self-management and pharmacist-led patient self-management in hong kong: a focus group study from different healthcare professionals' perspectives. BMC Health Serv Res 2011;11:121.

19. Salim AM, Elgizoli B. Exploring self-perception of community pharmacists of their professional identity, capabilities and role expansion. J Res Pharm Pract 2016;5:116-20.

20. Warchal S, Brown D, Tomlin M, Portlock J. Attitudes of successful candidates of supplementary prescribing courses to their training and their extended roles. Pharm J 2006;276:348-52.

21. Malangu $\mathrm{N}$. The future of community pharmacy practice in South Africa in the light of the proposed new qualification for pharmacists: implications and challenges. Global J Health Sci 2014;6:226-33.

22. You JH, Wong FY, Chan FW, Wong EL, Yeoh E. Public perception on the role of community pharmacists in self-medication and self-care in Hong Kong. BMC Clin Pharmacol 2011;11:19.

23. Berbatis CG, Sunderland VB, Joyce A, Bulsara M, Mills C. Enhanced pharmacy services, barriers and facilitators in Australia's community pharmacies: Australia's National Pharmacy Database Project. Int J Pharm Pract 2007;15:185-91.

24. Sadek MM, Elnour AA, Al Kalbani NMS, Bhagavathula AS, Baraka MA, Aziz AMA, et al. Community pharmacy and the extended community pharmacist practice roles: the UAE experiences. Saudi Pharm J 2016;24:563-70.

25. Fang Y, Yang S, Zhou S, Jiang M, Liu J. Community pharmacy practice in China: past, present and future. Int J Clin Pharm 2013;35:520-8.

26. Laliberte MC, Perreault S, Damestoy N, Lalonde L. Ideal and actual involvement of community pharmacists in health promotion and prevention: a cross-sectional study in Quebec, Canada. BMC Public Health 2012;12:192.

27. Sushilkumar PL, Mahendrakumar BJ, Baishnab S, Gloria Sam K, Chaitanya Kumar T. Implementation and evaluation of health screening services to diabetic and hypertensive patients in a selected community pharmacy at Belgaum City. Asian J Pharm Clin Res 2015;8:305-15.

28. Malik M, Kanwal N, Hussain A. Role of community pharmacist and nutritionists in obesity management: a literature review. Asian J Pharm Clin Res 2017;10:40-2. 